\title{
Mechanism of origin in two cases of chimerism
}

\author{
Antonella Minelli ${ }^{1,2 *}$, Andrea Guala ${ }^{3,4}$, Alberto Groppo ${ }^{1,2}$, Gabriella Restagno ${ }^{5}$, Roberto Lala $^{6}$, \\ Silvia Einaudi ${ }^{6}$, Mariaelena Repici ${ }^{6}$, Emilio Merlini ${ }^{7}$, Luca Sbaiz $^{5}$, Valentina Asnaghi ${ }^{5}$, \\ Ana Graciela Lopez ${ }^{8}$, Paola Angellotti ${ }^{3}$, Silvia Cristina ${ }^{9}$, Cesare Danesino ${ }^{1,2}$
}

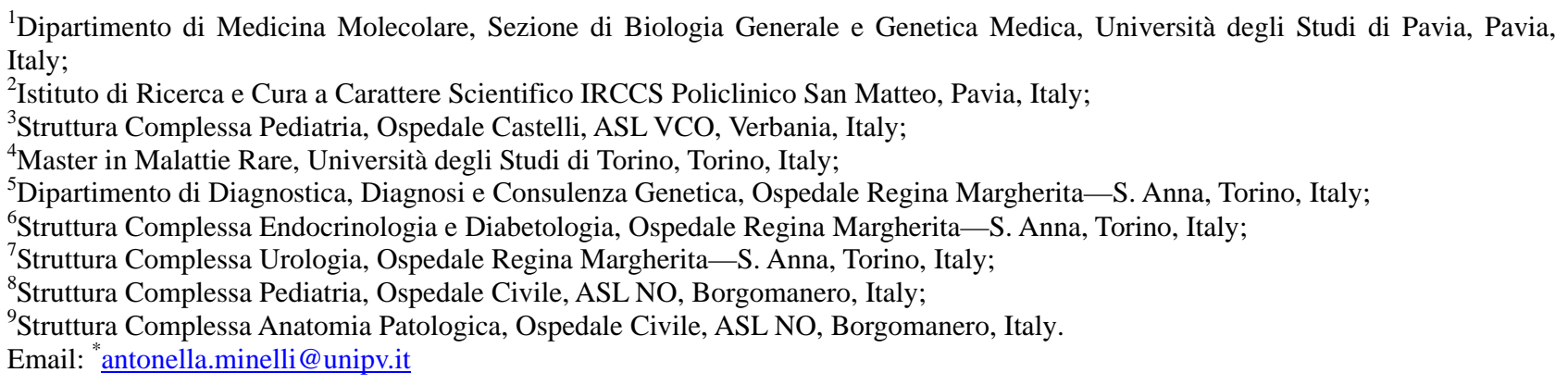

Received 3 October 2011; revised 16 November 2011; accepted 21 November 2011.

\section{ABSTRACT}

Chimerism is defined as the presence in a subject of more than one stable and genetically distinct cell line; cases reported so far include both patients with ambiguous genitalia and healthy subjects. The biological mechanisms, which may give origin to chimeras, are complex, and can be understood by analyzing DNA samples of the patients and their parents using molecular techniques. The objective of this study is to identify the mechanism of origin for the 2 cases we report. The first patient is a phenotipically normal girl with normal (external and internal) genitalia; the second patient had ambiguous genitalia and underwent surgery. DNA was purified from blood samples and, limited to Patient 1, from a sample of biliary cyst. Short tandem repeat polymorphisms were analyzed in order to identify the relative parental contribution to the patients. Molecular analyses carried out on the first patient are not fully informative because of two possible explanations (i.e. parthenogenetic and andrognetic chimera), while in the second case the presence of four alleles at some markers allowed us to identify a tetragametic chimera originnated from the fusion of two distinct embryos. Studies carried on one single tissue may not always be conclusive as they do not allow the precise identification of the mechanism of origin. In these cases, studies on more tissues are strongly suggested.

Keywords: Chimerism; Androgenetic Chimera; Parthenogenetic Chimera; Tetragametic Chimera; Microsatel- lite Polymorphism Analysis

\section{INTRODUCTION}

Chimerism is defined as the presence of more than one stable and genetically distinct cell line [1] originated independently from one another [2]. Thus chimerism is different from mosaicism, in which the cell lines have a common, single cell progenitor.

This condition is rare in humans: Malan et al. in 2006 counted about 30 cases [3] and this number increased a little in these last years.

When both female $(46, \mathrm{XX})$ and male $(46, \mathrm{XY})$ cell lines are present, the phenotype, ranging from normal male to normal female through various degree of ambiguous genitalia, is related to their distribution in the gonads. The ratio between the two cell lines in different tissues does not allow a precise prediction of the status of gonads or the phenotype of external genitalia [3].

The origin of the cell lines can be defined at a molecular level using a number of polymorphic markers and comparing the genetic profile of the patient with those of the parents. Only few cases, especially in these past years, have been studied this way, allowing to propose at least four different mechanisms of origin, namely tetragametic chimerism, parthenogenetic chimerism, chimera resulting from the fertilization of the second polar body and androgenetic chimerism. These mechanisms were reviewed by Malan in 2006 [3]; details are provided in the Discussion section of this paper.

We report two cases of chimerism in which molecular analysis allowed us to suggest either parthenogenetic or 
androgenetic origin in the first case and to identify a tetragametic mechanism of origin in the second.

\section{CASES REPORT}

\subsection{Patient 1}

Patient 1 was born at 37 weeks' gestation after an uneventful pregnancy, to healthy, unrelated Caucasian parents. Birth weight was 2600 g, length was $45 \mathrm{~cm}$, and head circumference was $43 \mathrm{~cm}$. Parental karyotype is normal.

Chorionic villus sampling was performed upon parental request, and the results showed two cell lines. One cell line with a 46,XX karyotype was seen in short term cultures, while a 46,XY cell line was observed in long term cultures. Control amniocentesis showed 46,XX in 21 clones from 3 independent cultures and 46,XY from 4 colonies from a single culture. Ultrasound examination consistently revealed a fetus with no malformations and with normal female external genitalia.

At birth, physical examination revealed a fully normal child with no malformations or dysmorphic features, and normal female external genitalia; abdominal ultrasound examination in the first week of life demonstrated the presence of normal uterus and ovaries.

The placenta showed morphological alterations suggestive of "chimerism": it weighed $1730 \mathrm{~g}$, and upon sectioning, a marginal area of vesicle formation consistent with molar changes was observed. At microscopic examination, the placental parenchyma showed mainly third trimester chorionic villi with widespread small artery lesions in both secondary and tertiary stem villi. There were marked villous hydrops with central cistern formation consistent with complete hydatidiform mole. The mixed population of morphologically normal chorionic villi and villi with the typical changes of complete hydatidiform mole was highly suggestive of placental/ fetal mosaicism [4,5]. These data, in addition to the results observed antenatally, were an indication to perform cytogenetic analysis of the newborn, which showed a 46,XX[31]/46,XY[19] karyotype. A similar ratio of the two cell lines was observed during follow up.

Normal development was recorded during follow up. At the age of 2, a slightly enlarged liver was found, and an ultrasound examination demonstrated a cystic formation of $7 \mathrm{~cm}$ which was diagnosed as a "congenital biliary cyst”, which was surgically removed.

\subsection{Patient 2}

Patient 2, Caucasian, was admitted to the hospital because of a sex determination disorder. Male sex was attributed at birth, but external genitalia, ambiguous and classified as Prader type III, were represented by the presence of a penoclitoris, perineal hypospadia, urogenital sinus, bifid scrotum and bilateral cryptorchidism.

At birth, chromosomal analysis on peripheral blood lymphocytes revealed two cell lines, 46,XX[49]/46,XY [15]. A second karyotype analysis few months later confirmed the presence of the two cell lines: 46,XX[67]/ 46,XY[33], while cultured fibroblasts from a skin biopsy showed only 46,XX[16]. Both parents showed normal karyotype. These results led to a diagnosis of 46,XX/ 46,XY chimerism.

QF-PCR analysis with chromosome specific probes (13, 18, 21, X and Y) revealed the presence of DNA belonging to two different cell lines, one female and one male. The X-chromosome signal proved to be stronger than the Y-chromosome signal.

Endocrine evaluation showed LH: $4.08 \mathrm{mU} / \mathrm{ml}$; estradiol: $8 \mathrm{pg} / \mathrm{ml}$; testosterone: $1.08 \mathrm{ng} / \mathrm{ml}$; all these values as well as 17OHP, androstenedione and DHEAS were within normal range. FSH $(9.45 \mathrm{mU} / \mathrm{ml})$ was out of range, and it was similar to what is observed in females.

Transabdominal ultrasound showed a uterus behind the bladder and two gonadal structures, while contrast $\mathrm{X}$-rays demonstrated a straight female-type urethra, vagina and uterus. Contrast medium reached the tubae bilaterally.

Laparoscopy revealed on the left side an uterus as well as a female gonad and tuba, with internal inguinal ring. On the right side, the internal inguinal ring was open and a testicular structure was present in the abdomen.

Detection of a morphologically normal uterus, together with a tuba and a female gonad led to decide to change the anatomical sex of the baby from male to female. This decision was discussed with the baby's parents and psychological support was provided. The baby underwent female genitoplasty with clitoral reduction. The right gonad was removed together with a cystic formation associated to it.

Histopathology of the gonadal tissue revealed the presence of ovarian parenchyma and testicular tissue, in particular seminiferous tubules with interstitial fibrosis and Leydig cells. Structures similar to rete testis, epididymis and vascular plexus were also detected. The finding was compatible with a diagnosis of ovotestis. The cystic structure was characterised by osteocartilaginous, thyroideal and mature connective tissue areas. Karyotyping was performed on a sample of the cystic tissue and resulted 46,XX. Histological diagnosis was of a mature cystic teratoma.

Biopsy was not performed on the left gonad because it presented with a macroscopically normal aspect, and in order to preserve the supposed ovarian tissue. 


\section{MATERIALS AND METHODS}

\subsection{DNA Purification}

After informed consent, blood samples from the two patients and their parents were obtained. Limited to Patient 1 , DNA was also purified from a fragment of biliary cyst surgically removed. DNA was purified by routine methods using GenElute ${ }^{\mathrm{TM}}$ Blood Genomic DNA Kit (Sigma-Aldrich ${ }^{\circledR}$ ).

\subsection{STRPs Analysis}

The short tandem repeat polymorphisms (STRPs) to be analysed were chosen on several different chromosomes, on the basis of their heterozygosity (see Table $\mathbf{1}$ and Table 2 for a complete list of markers for patient 1 and patient 2 respectively).

Genotyping of STRPs was performed using ABI PRISM $^{\mathrm{TM}}$ multicolor fluorescent dye technology, based on labeling DNA fragments with different color fluorescent dyes by PCR amplification. PCR conditions were developed in our lab. The PCR products are displayed as electropherograms showing fluorescence intensity as a function of fragment size or migration time. Peak Scanner Software ${ }^{\mathrm{TM}}$ v1.0 by Applied Biosystems provides peak detection (areas and heights) relative to alleles amplified as DNA fragments.

When parents shared an allele of the same size, we calculated the ratio between peak heights and compared it with the ratio of cell lines as demonstrated by cytogenetic analysis. This method allowed to assess the origin of that allele (maternal, paternal or both of them) and infer a single or double, maternal and/or paternal contribution.

\section{RESULTS}

We analyzed several STRPs localized on different autosomes, in addition to the $\mathrm{X}$ chromosome (see Table 1 and Table 2 for a complete list of markers for patient 1 and patient 2 respectively).

Informative and partially informative markers have been found. We defined a marker as informative when it allowed us to prove a double paternal and/or maternal contribution. A marker was considered partially informative when it showed three alleles and the origin of the extra allele could not be inferred because its origin could be maternal and/or paternal.

Table 1 and Table 3 show results for patient 1; Table 2 and Table 4 illustrate findings for patient 2. Figure 1 shows examples of informative markers for both patient 1 and 2.

\subsection{Patient 1}

Eight autosomal markers are informative, since they
Table 1. List of the STRPs studied for patient 1, showing size (in bp) and which alleles were observed in the patient and in her parents. Informative STRPs are shown in bold print (I: informative marker; N/I: not informative marker).

\begin{tabular}{|c|c|c|c|c|}
\hline STRP & Father & Mother & Patient & Notes \\
\hline D1S1609 & $178 / 194$ & $174 / 182$ & 178/182/194 & $\mathbf{I}^{d}$ \\
\hline D1S3723 & 182 & $190 / 194$ & $182 / 190$ & N/I \\
\hline D2S1361 & $170 / 186$ & & $165 / 186$ & $\mathrm{~N} / \mathrm{I}^{a}$ \\
\hline D2S2739 & 291/317 & & 291/301 & $\mathrm{N} / \mathrm{I}^{a}$ \\
\hline D3S4555 & $205 / 213$ & $205 / 209$ & $205 / 213$ & $\mathrm{~N} / \mathrm{I}^{a}$ \\
\hline D3S2406 & $330 / 346$ & 326 & $326 / 330 / 346$ & I \\
\hline D4S3355 & 136 & $136 / 144$ & $136 / 144$ & $\mathrm{~N} / \mathrm{I}^{a}$ \\
\hline D4S2426 & 260 & $248 / 264$ & $248 / 260$ & N/I \\
\hline D5S1470 & $170 / 186$ & & $166 / 186$ & $\mathrm{~N} / \mathrm{I}^{a}$ \\
\hline D5S815 & 286/290 & & $286 / 294$ & $\mathrm{~N} / \mathrm{I}^{a}$ \\
\hline D7S1808 & $255 / 273$ & $258 / 261$ & $255 / 258 / 273$ & $\mathbf{I}^{d}$ \\
\hline D7S1805 & $198 / 216$ & $198 / 216$ & 216 & N/I \\
\hline D7S1820 & $251 / 255$ & 263 & $251 / 255 / 263$ & I \\
\hline D7S796 & $176 / 184$ & $180 / 188$ & 176/180/184 & $\mathbf{I}^{d}$ \\
\hline D7S1830 & 221 & $221 / 225$ & $221 / 225$ & $\mathrm{~N} / \mathrm{I}^{a}$ \\
\hline D8S1130 & $133 / 137$ & $137 / 146$ & $133 / 137 / 146$ & $\mathbf{I}^{c}$ \\
\hline D8S586 & $244 / 252$ & $240 / 248$ & $244 / 248$ & $\mathrm{~N} / \mathrm{I}^{d}$ \\
\hline D10S189 & 185 & $183 / 185$ & $183 / 185$ & $\mathrm{~N} / \mathrm{I}^{a}$ \\
\hline D10S1779 & $266 / 268$ & $264 / 268$ & $264 / 266 / 268$ & $\mathbf{I}^{c}$ \\
\hline D10S547 & 237/239 & $239 / 247$ & $239 / 247$ & $\mathrm{~N} / \mathrm{I}^{a}$ \\
\hline D10S570 & 285/295 & $291 / 295$ & 291/295 & $\mathrm{N} / \mathrm{I}^{a}$ \\
\hline D12S390 & $139 / 154$ & 148 & $139 / 148$ & N/I \\
\hline D12S1586 & $157 / 169$ & $165 / 167$ & $157 / 165$ & N/I \\
\hline 15DUP10 & 398 & 395 & $395 / 398$ & N/I \\
\hline 15DUP12 & 238 & 234 & $234 / 238$ & $\mathrm{~N} / \mathrm{I}$ \\
\hline D15S822 & $284 / 288$ & $260 / 264$ & $260 / 284 / 288$ & I \\
\hline D15S643 & $195 / 213$ & 217 & $195 / 213 / 217$ & I \\
\hline COMPLEX & $264 / 268$ & $264 / 268$ & $264 / 268$ & N/I \\
\hline EVI20 & $191 / 193$ & 191 & $191 / 193$ & $\mathbf{I}^{b}$ \\
\hline D20S604 & $137 / 141$ & 137/141 & 137 & N/I \\
\hline D20S1151 & $251 / 279$ & $243 / 247$ & $243 / 279$ & $\mathrm{~N} / \mathrm{I}^{d}$ \\
\hline DXS9908 & 222 & $224 / 230$ & $222 / 224$ & $\mathbf{I}$ \\
\hline GATA172D05 & 106 & $114 / 126$ & $106 / 126$ & $\mathbf{I}^{d}$ \\
\hline
\end{tabular}

${ }^{a}$ The two alleles show peaks of similar size; ${ }^{b}$ STRP demonstrating double paternal contribution; ${ }^{c}$ Only partially informative marker; ${ }^{d}$ Data consistent with those found analyzing the biliary cyst. 
Table 2. List of the STRPs studied for patient 2, showing size (in bp) and which alleles were observed in the patient and in her parents. Informative STRPs are shown in bold print. (I: informative marker; N/I: not informative marker).

\begin{tabular}{|c|c|c|c|c|}
\hline STRP & Father & Mother & Patient & Notes \\
\hline D1S3723 & $186 / 190$ & $145 / 186$ & $145 / 186$ & $\mathbf{I}^{b}$ \\
\hline D1S1609 & 190/202 & 178/186 & 178/186/190 & I \\
\hline D2S1361 & 175/183 & 179/183 & 175/179/183 & $I^{c}$ \\
\hline D3S2406 & 330 & $326 / 342$ & 326/330/342 & I \\
\hline D5S1470 & $182 / 190$ & 186/194 & $182 / 186 / 190 / 194$ & I \\
\hline D5S815 & $256 / 290$ & $286 / 290$ & $256 / 286 / 290$ & $I^{c}$ \\
\hline D7S1805 & 213/217 & $198 / 221$ & $198 / 213 / 217 / 221$ & I \\
\hline D7S796 & 188 & $176 / 191$ & 176/188/191 & I \\
\hline D8S1130 & $132 / 150$ & $132 / 141$ & 132 & $\mathrm{~N} / \mathrm{I}$ \\
\hline D10S1779 & 265 & $274 / 276$ & $265 / 274 / 276$ & I \\
\hline D10S570 & 288 & 294 & $288 / 294$ & $\mathrm{~N} / \mathrm{I}$ \\
\hline D12S390 & 148/157 & 152/157 & $148 / 152 / 157$ & $I^{c}$ \\
\hline D15S643 & 209/213 & 209 & 209/213 & $\mathrm{N} / \mathrm{I}^{a}$ \\
\hline D20S1151 & $246 / 274$ & $246 / 250$ & $246 / 250 / 274$ & $\mathbf{I}^{c}$ \\
\hline DXS9908 & 224 & 228 & $224 / 228$ & $\mathbf{I}$ \\
\hline GATA172D05 & 130 & $114 / 122$ & 114/122/130 & I \\
\hline
\end{tabular}

${ }^{a}$ The two alleles show peaks of similar size; ${ }^{b}$ STRP demonstrating double maternal contribution; ${ }^{c}$ Only partially informative marker.

Table 3. Peak heights (in relative fluorescent units) and their ratios for STRPs showing two different alleles, and the parents sharing one of them for patient 1 .

\begin{tabular}{cccccc}
\hline \multirow{2}{*}{ STRP } & \multicolumn{2}{c}{ Allele 1 } & \multicolumn{2}{c}{ Allele 2 } & \multirow{2}{*}{ Ratio } \\
\cline { 2 - 5 } & Size (bp) & Height & Size (bp) & Height & \\
\hline D2S1361 & 165 & 8876 & 186 & 8578 & 1.03 \\
D2S2793 & 291 & 6720 & 301 & 6437 & 1.04 \\
D3S4555 & 205 & 6418 & 213 & 3632 & 1.76 \\
D4S3355 & 136 & 3049 & 144 & 2810 & 1.09 \\
D5S1470 & 166 & 2555 & 186 & 2658 & 1.04 \\
D5S815 & 286 & 4461 & 294 & 4166 & 1.07 \\
D7S1830 & 221 & 268 & 225 & 241 & 1.11 \\
D10S189 & 183 & 570 & 185 & 703 & 1.23 \\
D10S547 & 239 & 215 & 247 & 185 & 1.16 \\
D10S570 & 291 & 977 & 295 & 630 & 1.55 \\
EVI20 & 191 & 1794 & 193 & 661 & 2.71 \\
\hline
\end{tabular}

Table 4. Peak heights (in relative fluorescent units) and their ratios for STRPs showing two different alleles, and parents sharing one of them for patient 2 .

\begin{tabular}{cccccc}
\hline \multirow{2}{*}{ STRP } & \multicolumn{2}{c}{ Allele 1 } & \multicolumn{2}{c}{ Allele 2 } & \multirow{2}{*}{ Ratio } \\
\cline { 2 - 5 } & Size (bp) & Height & Size (bp) & Height & \\
\hline D1S3723 & 145 & 767 & 186 & 1494 & 1.95 \\
D15S643 & 209 & 157 & 213 & 134 & 1.17 \\
\hline
\end{tabular}

show double paternal and single maternal contribution. As regards EVI20, it has been considered an informative marker because the ratio between peak heights is consistent with the ratio of cytogenetic analysis (see Table 3). Markers D8S1130 and D10S1779 reveal three alleles and are reckoned partially informative, because the origin of the extra allele cannot be assessed.

$\mathrm{X}$-linked markers are informative, since they show double paternal (considering the $\mathrm{Y}$ chromosome) and single maternal contribution.

The same results were observed when analyzing DNA extracted from biliary cyst, tested only for D1S1609, D7S1808, D7S796, D8S586, D20S1151 and GATA 172D05 markers.

The 10 informative markers clearly reveal double paternal contribution, while, up to now, double maternal contribution has never been proven.

\subsection{Patient 2}

Two informative markers (D5S1470 and D7S1805) on 2 chromosomes show 4 different alleles, proving a double maternal and double paternal contribution.

In addition, other 5 autosomal markers are also informative, since they show double maternal and single paternal contribution. Though marker D1S3723 shows only two alleles, it has been considered an informative marker, because the ratio between peak heights is consistent with the ratio of cytogenetic analysis (see Table 4).

Four markers are partially informative, since they show three different alleles and the origin of the extra allele cannot be assessed.

Both X-linked markers are informative because they show double paternal contribution (considering the $\mathrm{Y}$ chromosome).

Moreover, marker GATA172D05 shows double maternal contribution.

On the whole, these data are consistent with double paternal and double maternal contributions for this case.

\section{DISCUSSION}

Since chimerism is characterized by the independent origins of the two cell lines, three or four alleles at a 


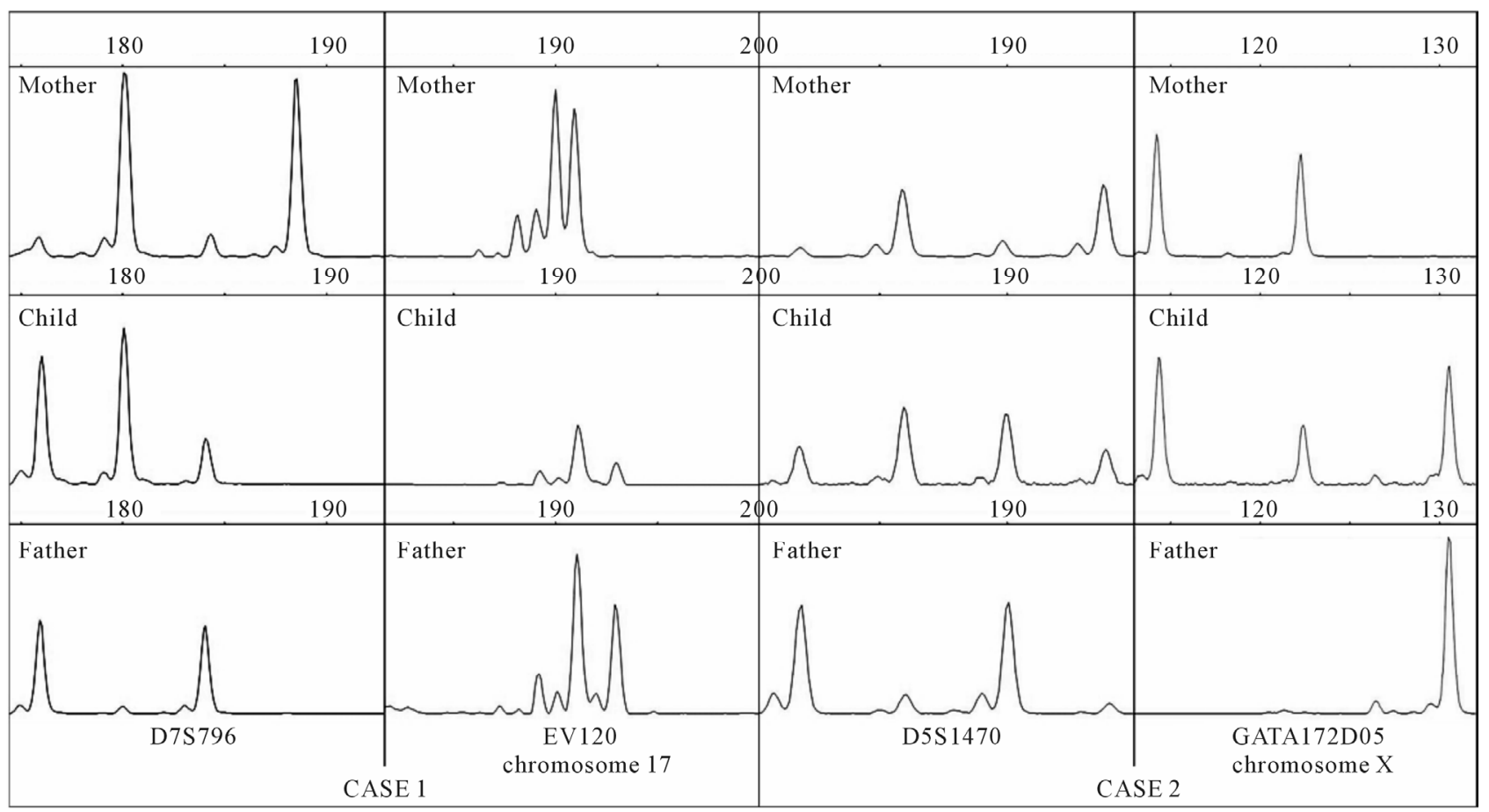

Figure 1. Examples of informative markers for patient 1 (on the left) and patient 2 (on the right). Mothers' electropherograms in the higher row, fathers' in the lower and patients' in the middle.

specific locus or skewed dosage of two alleles can be observed [2]. The interpretation of results, even in conjunction with clinical data, may be difficult in some cases, since they may not allow the identification of the precise mechanism of origin. The mechanisms of origins are summoned in Table 5 and are now discussed in some detail.

\subsection{Tetragametic Chimerism}

The fusion of two different and independently fertilized zygotes leads to the tetragametic chimera. This mechanism is the most frequent and, to date, it has been demonstrated in 9 patients reported [2,6-13]. In this case, 4 different alleles ( 2 maternal and 2 paternal) can be observed at some loci in the patient.

\subsection{Parthenogenetic Chimerism}

The parthenogenetic chimera generally arises from an oocyte undergoing parthenogenetic activation, giving rise to two identical daughter cells which are then fertilized by two different spermatozoa. This mechanism ("Parthenogenetic/1" in Table 5), described by Giltay, has been demonstrated only once [14]. In this case, 3 alleles ( 2 paternal and 1 maternal) can be observed at some loci in the patient.

However, this is not the only mechanism which can result in such a chimera. In fact, a similar but slightly different mechanism was proposed and demonstrated by
Strain and colleagues in 1995 ("Parthenogenetic/2" in Table 5) [15]. The authors proposed a parthenogenetic activation of the oocyte, producing 2 identical maternal cells. One of these cells was then fertilized by a Y-bearing sperm, while the other underwent diploidization, producing a parthenogenetic cell line. In this case, the parthenogenetic cell line must show only one maternal allele, whereas the other cell line may show two alleles (1 paternal and 1 maternal) at some loci in the patient. When analyzing a tissue made up of these two cell lines, 2 alleles can be observed at some loci in the patient, since the two cell lines share the same maternal alleles.

\subsection{Chimera Resulting from the Fertilization of the Second Polar Body}

Though often considered, the fertilization of the second polar body has never been proved at a molecular level. This mechanism requires a normal fertilization followed by the extrusion of the second polar body and its fertilization by a second spermatozoon. In this case, some distal markers may show 4 alleles (2 paternal and 2 maternal), while centromeric markers may show 3 alleles ( 2 paternal and 1 maternal) at some loci in the patient. These differences are due to crossing-over events occurring during meiosis. Since second polar body fertilization and parthenogenetic chimera may show similar molecular results, neither mechanism can be ruled out with certainty in the cases reported by Chen, Draper, and 
Table 5. Mechanisms of origin of chimeras, possible results of STRP analysis and related references. In case of parthenogenetic and androgenetic chimerism, different authors suggested different mechanisms resulting in such chimeras.

\begin{tabular}{ccccc}
\hline Mechanism of origin & $\begin{array}{c}\text { Paternal } \\
\text { contribution }\end{array}$ & $\begin{array}{c}\text { Maternal } \\
\text { contribution }\end{array}$ & $\begin{array}{c}\text { Max number of alleles that may be } \\
\text { observed in the patient }\end{array}$ & References \\
\hline Tetragametic & 2 & 2 & 4 & $2,6-13$ \\
Parthenogenetic/1 & 2 & 1 & 2 & 14 \\
Parthenogenetic/2 & 1 & 1 & $3 / 4^{a}$ & 2 \\
Fertilization of the second polar body & 2 & $2 / 3^{a}$ & 3 & $19-20$ \\
Androgenetic/1 & 1 & 1 & 3 & 21 \\
Androgenetic/2 & 2 & 1 & 3 & 22 \\
Androgenetic/3 & 2 & 1 & 22 \\
Androgenetic/4 & 2 & 1 & 3
\end{tabular}

${ }^{a}$ Due to crossing-over events during meiosis, centromeric markers may show 3 maternal alleles, whereas distal markers may show only 2, thus altering the maximum number of alleles in a tissue made up of 2 cell lines.

Mosebach [16-18].

\subsection{Androgenetic Chimera}

After a normal event of fertilization of an oocyte and a X spermatozoon, endoreplication of the paternal pronucleous takes place; the following cell cleavage leads to a diploid (with maternal and paternal pronuclei) and a haploid (with only a paternal pronucleus) cells. A second event of endoreplication of the paternal genome in the haploid cell brings to the androgenetic cell line. This mechanism has been demonstrated twice $[19,20]$. In this case, the androgenetic cell line must show only one paternal allele, whereas the other cell line may show two different alleles (1 paternal and 1 maternal) at some loci in the patient. When analyzing a tissue made up of these two cell lines, 2 alleles can be observed at some loci in the patient, since the two cell lines share the same paternal alleles ("Androgenetic/1" in Table 5).

A related mechanism was proposed by Surti in 2005 [21]: it requires the fusion of a normal zygote (fertilized by a Y-carrying spermatozoon) and an empty oocyte fertilized by a X-carrying spermatozoon and undergone to endomitosis. This second mechanism has been demonstrated only once. In this case, the androgenetic cell line must show only one paternal allele, while the other cell line may show two different alleles (1 paternal and 1 maternal) at some loci in the patient. When analyzing a tissue made up of these two cell lines, 3 alleles can be found at some loci in the patient, since the two cell line originated from two different spermatozoa ("Androgenetic/2" in Table 5). We would like to point out that Surti described the placenta as cystic when reporting the clinical history, and that chimerism was confined to the placenta [21].

Furthermore, other 2 mechanisms, each involving a tri-pronuclear (3PN) zygote, were proposed by Robinson in 2007 [22]. The authors suggested that, after the fertilization of an oocyte with two normal spermatozoa (leading to a 3PN zygote), fully diploid two-celled embryos can occur when only one of the three haploid genomes replicates and segregates at the end of the onecell stage. In this case, the androgenetic cell line may show 2 alleles (both paternal) at some loci in the patient, whereas the other cell line may show 2 alleles (1 paternal and 1 maternal) at some loci. When analyzing a tissue made up of these two cell lines, 3 alleles may be found at some loci in the patient, because 2 spermatozoa are involved ("Androgenetic/3" in Table 5).

Alternatively, such embryos can also arise when a 3PN zygote undergoes cell division without genome replication, leading to a diploid and a haploid cell, and consequent replication of the haploid genome. In this case, the androgenetic cell line must show only one paternal allele, while the other cell line may show two different alleles ( 1 paternal and 1 maternal) at some loci in the patient. When analyzing a tissue made up of these two cell lines, 3 alleles can be found at some loci in the patient, because 2 spermatozoa are involved ("Androgenetic/4” in Table 5).

It is worth noting that in cases of androgenetic chimerism, complete hydatidiform moles, placental mesenchimal dysplasia, cystic placenta, hemangiomas and liver cysts are often found during pregnancy [22].

\subsection{Patient 1}

Results showed 3 alleles at some loci, two of them have a paternal origin, while the remaining is maternal. Hence they are consistent with both parthenogenetic and androgenetic hypothesis. Considering both molecular analysis and the clinical description of the placenta, we considered the androgenetic hypothesis very likely. We then studied other tissues in order to identify an androgenetic 
cell line alone which could support this hypothesis, but we were not able to find it. Based on these data, we cannot rule out either mechanism.

\subsection{Patient 2}

Results are consistent only with tetragametic chimerism, since it is the only hypothesis which can explain the 4 alleles we found.

\section{CONCLUSIONS}

A routine chromosome analysis on a single tissue may not identify all cases of chimerism (in fact, in case 2 fibroblasts only show a 46,XX karyotype). In addition, even when two cell lines are observed in one single tissue, the interpretation of results may not lead to the clear identification of the mechanism which gave rise to the chimera. It is therefore strongly suggested to study more than one tissue in patients with ambiguous genitalia, in order to rule out the possibility of chimerism or mosaicism and to identify clearly the mechanism of origin.

In every case of ambiguous genitalia, sistematic survelliance is certanly needed to check the oncologic risk of the dysgenetic gonad. It is currently still a matter of debate whether ultrasound examination alone can be used as a reliable method for diagnosing the presence of structural abnormalities in the gonads, or biopsy should be performed in all cases. Biochemical markers of neoplasia ought to be, of course, included in follow up [23-25].

Specific counseling issues arise when chimerism is diagnosed prenatally [12]. In fact it is not possible to predict what the phenotype will be at term, since it may range from completely normal to the presence of ambiguous genitalia.

Chimerism is an interesting biological problem, in which the genotype-phenotype correlation is still far from being defined. Moreover, given that chimeras can be phenotypically normal male or female, and since the number of cases studied is, up to now, limited, it is reasonable to assume that chimeras are under-diagnosed and less rare than previously believed. Accurate clinical examination and extended genetic investigations will provide new insights into the biological questions still pending.

\section{ACKNOWLEDGEMENTS}

Dr. Andrea Guala achieved a Master in Rare Diseases at Università degli Studi di Torino, Italy.

\section{REFERENCES}

[1] Koenigsberg, R. (Ed.) (1994) Churchill's Medical Dictionary. Centro Scientifico Editore, 355.
[2] Ramsay, M., Pfaffenzeller, W., Kotze, E., Bhengu, L. and Essop, F. (2009) Chimerism in black southern african patients with true hermaphroditism 46,XX/47XY,+21 and 46,XX/46,XY. Annals of the New York Academy of Sciences, 1151, 68-76. doi:10.1111/j.1749-6632.2008.03570.x

[3] Malan, V., Vekemans, M. and Turleau, C. (2006) Chimera and other fertilization errors. Clinical Genetics, 70, 363-373. doi:10.1111/j.1399-0004.2006.00689.x

[4] Makrydimas, G., Sebire, N., Thornton, S., Zagorianakou, N. and Lolis, D. (2002) Complete hydatidiform mole and normal live birth: A novel case of confined placental mosaicism: Case report. Human Reproduction, 17, 24592463. doi:10.1093/humrep/17.9.2459

[5] Golubovsky, M.D. (2003) Postzygotic diploidization of triploids as a source of un usual cases of mosaicism, chimerism and twinning. Human Reproduction, 18, 236242. doi:10.1093/humrep/deg060

[6] Green, A., Barton, D., Jenks, P., Pearson, J. and Yates, J. (1994) Chimaerism shown by cytogenetics and DNA polymorphism analysis. Journal of Medical Genetics, 31, 816-817. doi:10.1136/jmg.31.10.816

[7] Uehara, S., Nata, M., Nagae, M., Sagisaka, K. and Okamura, K. (1995) Molecular biologic analyses of tetragametic chimerism in a true hermaphrodite with 46,XX/46,XY. Fertility and Sterilility, 63, 189-192.

[8] Bonthron D.T., Strain L. and Dean J.C.S. (1997) Amalgamation of in vitro fertilized embryos, resulting in birth of a true hermaphrodite chimera. American Journal of Human Genetics, Supplement to Volume 61, A147.

[9] Strain, L., Dean, J.C.S., Hamilton, M.P.R. and Bonthron, D.T. (1998) A true hermaphrodite chimera resulting from embryo amalgamation after in vitro fertilization. New England Journal of Medicine, 338, 166-169. doi:10.1056/NEJM199801153380305

[10] Yu, N., Kruskall, M.S., Yunis, J.J., Knoll, J.H.M. and Uhl, L. (2002) Disputed maternity leading to identification of tetragametic chimerism. New England Journal of Medicine, 346, 1545-1552.doi:10.1056/NEJMoa013452

[11] Drexler, C., Glock, B., Vadon, M., Staudacher, E. and Dauber, E.M. (2005) Tetragametic chimerism detected in a healthy woman with mixed field agglutination reactions in ABO blood grouping. Transfusion, 45, 698-703. doi:10.1111/j.1537-2995.2005.04304.x

[12] Malan, V., Gesny, R., Morichon-Delvallez, N., Aubry, M. and Benachi, A. (2007) Prenatal diagnosis and normal outcome of a 46,XX/46,XY chimera: A case report. $\mathrm{Hu}$ man Reproduction, 22, 1037-1041. doi:10.1093/humrep/del480

[13] Verdiani, S., Bonsignore, A., Casarino, L., Ferrari, G. and Zia, S. (2009) An unusual observation of tetragametic chimerism: Forensic aspects. International journal of legal medicine, 123, 431-435. doi:10.1007/s00414-009-0332-0

[14] Giltay, J.C., Brunt, T., Beemer, F.A., Wit, J.M. and Ploos Van Amstel, H.K. (1998) Polymorphic detection of a parthenogenetic maternal and double paternal contribution to a 46,XX/46,XY hermaphrodite. The American Journal of Human Genetics, 62, 937-940. doi:10.1086/301796

[15] Strain, L., Warner, J.P., Johnston, T. and Bonthron, D.T. (1995) A human parthenogenetic chimaera. Nature Gene- 
tics, 11, 164-169. doi:10.1038/ng1095-164

[16] Chen, C.P., Chern, S.R., Sheu, J.C., Lin, S.P. and Hsu, C.Y. (2005) Prenatal diagnosis, sonographic findings and molecular genetic analysis of a 46,XX/46, XY true hermaphrodite chimera. Prenatal diagnosis, 25, 502-506. doi:10.1002/pd.1181

[17] Draper, N.L., Conley, C., Smith, C. and Benson, K. (2008) Dispermic chimerism identified during HLA typing for stem cell transplantation. Transfusion, 48, 13981402. doi:10.1111/j.1537-2995.2008.01711.x

[18] Mosebach, M., Parkner, A., Jakubiczka, S., Wieacker, P. and Heim, M.U. (2006) Dispermic chimerism identified during blood group determination and HLA typing. Transfusion, 46, 1978-1981. doi:10.1111/j.1537-2995.2006.01005.x

[19] Kaiser-Rogers, K.A., Mcfadden, D.E., Livasy, C.A., Dansereau, J. and Jiang, R. (2006) Androgenetic/biparental mosaicism causes placental mesenchymal dysplasia. Journal of Medical Genetics, 43, 187-192. doi:10.1136/jmg.2005.033571

[20] Giurgea, I., Sanlaville, D., Fournet, J. C., Sempoux, C. and Bellanne-Chantelot, C. (2006) Congenital hyperinsulinism and mosaic abnormalities of the ploidy. Journal of Medical Genetics, 43, 248-254. doi:10.1136/jmg.2005.034116

[21] Surti, U., Hill, L. M., Dunn, J., Prosen, T. and Hoffner, L.
(2005) Twin pregnancy with a chimeric androgenetic and biparental placenta in one twin displaying placental mesenchymal dysplasia phenotype. Prenatal Diagnosis, 25, 1048-1056. doi:10.1002/pd.1255

[22] Robinson, W.P., Lauzon, J.L., Innes, A.M., Lim, K. and Arsovska, S. (2007) Origin and outcome of pregnancies affected by androgenetic/biparental chimerism. Human Reproduction, 22, 1114-1122. doi:10.1093/humrep/del462

[23] Hughes, I.A., Nihoul-Fékété, C., Thomas, B. and CohenKettenis, P. (2007) Consequences of the ESPE/LWPES guidelines for diagnosis and treatment of disorders of sex development. Best Practice \& Research Clinical Endocrinology \& Metabolism, 21, 351-365. doi:10.1016/j.beem.2007.06.003

[24] Looijenga, L.H.J., Hersmus, R., Oosterhuis, J.W., Cools, M. and Drop, S.L.S. (2007) Tumor risk in disorders of sex development (DSD). Best Practice \& Research Clinical Endocrinology \& Metabolism, 21, 480-495. doi:10.1016/j.beem.2007.05.001

[25] Cools, M., Drop, S.L.S., Wolffenbuttel, K.P., Oosterhuis, J.W. and Looijenga, L.H.J. (2006) Germ cell tumors in the intersex gonad: Old paths, new directions, moving frontiers. Endocrine reviews, 27, 468-484. doi:10.1210/er.2006-0005 